Session 2330

\title{
Exploration of Collective Efficacy Beliefs in Student Project Teams: Implications for Student and Team Outcomes
}

\author{
Robert W. Lent, Linda Schmidt, Janet Schmidt, and Gary Pertmer \\ University of Maryland, College Park
}




\begin{abstract}
This study extends Bandura's $\left(1997^{2}\right)$ concept of collective efficacy to the context of student project teams in engineering education. Students participating in an introductory engineering design or a senior-level engineering course completed measures of collective efficacy (beliefs about the capabilities of their project teams), team cohesion, and satisfaction with the team experience. Findings indicated that collective efficacy (a) was strongly related to team cohesion and satisfaction; (b) partially mediated the relationship between team cohesion and satisfaction, and (c) was moderated related to other social cognitive measures (e.g., self-efficacy, interest) regarding pursuit of an engineering major. In addition, more advanced students reported significantly stronger collective efficacy regarding their teams than did introductory-level students. Our presentation will consider the implications of these findings for further research and theory on team functioning within educational and work settings.
\end{abstract}


Social cognitive career theory (SCCT; Lent, Brown, \& Hackett, 1994 ${ }^{6}$ ) has become an influential approach to understanding academic and career behavior. SCCT was designed to explain the processes through which people develop career and educational interests, translate their interests into occupationally-relevant choices, and achieve varying levels of performance and persistence in academic and work domains. One of the theory's most frequent applications has been in exploring students' engagement in math and science-related fields (e.g., Fouad \& Smith, $1996^{4}$; Gainor \& Lent, 19985 Lopez, Lent, Brown, \& Gore, $1997^{7}$ ), and several studies have specifically examined SCCT in relation to engineering student academic outcomes (e.g., Schaefers, Nauta, \& Epperson, $\left.1997^{10}\right)$.

This presentation is part of a multistage research program focusing on SCCT within the context of engineering education. In the first stage of this program, we examined SCCT's utility in explaining the interests and major choice goals of freshmen engineering students (Schmidt, Lent, Schmidt, Mead, \& Bigio, $2001^{11}$ ). Findings indicated that (a) self-efficacy (personal beliefs regarding one's academic capabilities in engineering) and outcome expectations (beliefs that majoring in engineering will lead to personally valued outcomes) were good predictors of students' interests, and (b) the set of social cognitive variables (including environmental supports and barriers) was strongly predictive of students' academic goals. 
In this second stage of the research program, we extend research on SCCT by examining collective efficacy beliefs, a social cognitive construct that has not previously been studied within engineering education. Whereas self-efficacy involves individual's beliefs regarding their solitary capabilities, collective efficacy refers to group participants' beliefs about the ability of their group to perform its assigned tasks and to work effectively together as a unit, rather than as individuals. Collective efficacy beliefs have been found to affect group-level processes and outcomes (e.g., group goal-setting, productivity) in other contexts, such as business organizations and athletic teams (Bandura, 1997 ${ }^{2}$ ). Given the prominent role that student project teams have recently attained in engineering education $\left(\mathrm{ABET}, 2000^{1}\right.$ ), it seems important to study group-level variables, such as collective efficacy beliefs, that may both shed light on project team functioning and suggest ways to assist team members to work together more effectively.

In the present study, we developed a measure of collective efficacy beliefs linked to student team functioning and administered it, along with several other measures, to students enrolled either in an introductory design course or a senior-level electrical engineering course. We were specifically interested in addressing three research questions. First, to what extent (and in what ways) are collective efficacy beliefs related to students' ratings of the team environment (e.g., cohesion or level of unity among team members) and satisfaction with the team experience? (Figure 1 illustrates hypothesized linkages between these constructs.) Second, are collective efficacy beliefs related to students' sense of self-efficacy, interests, and social support relative to the engineering environment? Third, do seniors (who have had more experience with project teams) differ 
from students in an introductory course regarding perceptions of their teams' collective efficacy?

\section{Method}

Participants were 190 students enrolled either in an introductory engineering design course $(\underline{n}=165)$ or a senior-level electrical engineering course $(\underline{n}=25)$ at a large Eastern university. Most of the participants were men (81\%; 19\% were women). They completed a battery of measures including collective efficacy, team cohesion, satisfaction with team functioning, self-efficacy, outcome expectations, technical interests, major choice goals, and social supports and barriers relative to pursuit of an engineering major. (Psychometric data for the measures can be obtained from the first author.)

\section{Results}

Relative to our first research question, findings indicated that students' collective efficacy beliefs were substantially related to team cohesion $(\underline{r}=.67)$ and satisfaction $(\underline{r}=$ .80) ratings (see Table 1). Thus, members who viewed their project teams as efficacious were likely to experience their teams as cohesive, or harmonious, and to be satisfied with the team experience; conversely, those with lower collective efficacy percepts were less satisfied with their team's functioning and saw their teams as less cohesive. Team cohesion and satisfaction were also strongly interrelated, $\underline{r}=.84$.

Next, we tested the hypotheses that (a) satisfaction with the team experience would be better predicted by the combination of team cohesion and collective efficacy than by either predictor alone, and (b) collective efficacy would partly mediate the relation 
between team cohesion and satisfaction (see Figure 1). To test these hypotheses, we performed a hierarchical regression, entering collective efficacy and team cohesion at successive steps of the equation. Collective efficacy explained a substantial amount of variance at the first step $\left(\underline{\mathrm{R}}^{2}=.65\right)$, and team cohesion accounted for additional significant variance $\left(? \underline{\mathrm{R}}^{2}=.16\right)$ at the second step. Together, the two predictors explained $81 \%$ of the variance in satisfaction (compared to roughly two-thirds of the variance individually) and both yielded significant beta weights (for collective efficacy, $\beta=.44$; for cohesion, $\beta=$ $.55, \mathrm{p}<.001)$. The drop in variance accounted for by team cohesion after controlling for collective efficacy is consistent with the hypothesis that cohesion affects satisfaction both directly and indirectly, via collective efficacy.

Regarding our second research question, collective efficacy beliefs were found to correlate moderately and significantly with each of the other social cognitive variables ( $\underline{r}$ 's ranged between .36 and $.49 ; \underline{p}<.001)$, with the exception of social barriers $(\underline{r}=-.09)$. Thus, more favorable collective efficacy beliefs were associated with higher self-efficacy, outcome expectations, interests, goals, and social support (see Table 1).

Finally, to address the third research question, we compared the collective efficacy scores of the students in the introductory design class versus those in the senior electrical engineering course. An independent samples t-test revealed that collective efficacy did differ significantly among the two groups, $\underline{\mathrm{t}}(185)=3.32, \underline{\mathrm{p}}<.001$, with the seniors reporting stronger collective efficacy regarding their project teams $(\underline{\mathrm{M}}=8.18 ; \underline{\mathrm{SD}}=.87)$ than did students in the introductory design class $(\underline{\mathrm{M}}=7.06 ; \underline{\mathrm{SD}}=1.65)$. In terms of 
practical significance (Cohen's $\mathrm{d}^{3}$ ), the two groups differed by .85 standard deviations, which is considered a large effect size in the social sciences (Cohen, 1988).

\section{Discussion}

The present findings offer preliminary support for the utility of collective efficacy as a concept for understanding the functioning of student project teams. In particular, collective efficacy and cohesion were found to jointly predict team-related satisfaction, with each variable explaining unique variance. We also found support for a hypothesized model in which collective efficacy partly mediated the relationship between team cohesion and satisfaction. In addition, collective efficacy beliefs were found to relate to a variety of individual-level social cognitive variables, including self-efficacy, outcome expectations, interests, goals, and social supports relative to pursuing an engineering major.

It is also noteworthy that we found a significant difference between the collective efficacy beliefs of students in an introductory design course versus those in a senior-level engineering course. Although caution is necessary in interpreting these findings due to the lack of experimental controls, the higher collective efficacy scores of the seniors might reflect their greater experience with project teams, including their acquisition of skills at forming and maintaining effective teams. Further research, utilizing experimental and longitudinal designs, would be useful in exploring this issue. However, the present findings, in concert with prior research (e.g., Prussia \& Kinicki, $1996^{11}$ suggest the possibility that intentional efforts at team-building (e.g., providing the team with ongoing feedback on its performance) can foster development of collective efficacy beliefs along with the skills that students need to function effectively as project team members. 
On balance, these findings support the need for further study of group learning and productivity processes in the academic and career development literatures. Student teams are becoming an increasingly popular educational medium in engineering, business, and other academic fields, mirroring the prominence of teams in the workplace. Thus, it is important to examine theoretical mechanisms, like collective efficacy, that may both shed light on team functioning under natural conditions and suggest developmental or remedial steps for promoting effective teamwork. Our presentation will consider new directions for research and educational practice relative to collective efficacy and team functioning in engineering. 


\section{Bibliographic Information}

1. ABET (2000). Engineering Criteria 2000. Baltimore, MD: Accrediting Board for

Engineering and Technology.

2. Bandura, A. (1997). Self-efficacy: The exercise of control. New York: W.H. Freeman.

3. Cohen, J. (1988). Statistical power analysis for the behavioral sciences $\left(2^{\text {nd }}\right.$ ed.). Hillsdale,

NJ: Erlbaum.

4. Fouad, N.A., \& Smith, P.L. (1996). A test of a social cognitive model for middle school students: Math and science. Journal of Counseling Psychology, 43, 338-346.

5. Gainor, K.A., \& Lent, R.W. (1998). Social cognitive expectations and racial identity attitudes in predicting the math choice intentions of Black college students. Journal of Counseling Psychology, 45, 403-413.

6. Lent, R. W., Brown, S. D., \& Hackett, G. (1994). Toward a unifying social cognitive theory of career and academic interest, choice, and performance [Monograph]. Journal of Vocational Behavior, 45, $79-122$.

7. Lopez, F.G., Lent, R.W., Brown, S.D., \& Gore, P.A. (1997). Role of social-cognitive expectations in high school students' mathematics-related interest and performance. Journal of Counseling Psychology, $\underline{44}, 44-52$.

8. Nauta, M.M., Epperson, D.L., \& Kahn, J.H. (1998). A multiple-groups analysis of predictors of higher level career aspirations among women in mathematics, science, and engineering majors? Journal of Counseling Psychology, 45, 483-496.

9. Prussia, G.E., \& Kinicki, A.J. (1996). A motivational investigation of group effectiveness using social cognitive theory. Journal of Applied Psychology, 81, 187-198.

10. Schaefers, K.G., Epperson, D.L., \& Nauta, M.M. (1997). Women's career development: Can theoretically derived variables predict persistence in engineering majors? Journal of Counseling Psychology, 44, 173-183. 
11. Schmidt, J., Lent, R.W., Schmidt, L., Mead, P., \& Bigio, D. (2001, June). Social cognitive theory as an approach to understanding retention in engineering majors. Paper presented at the meeting of the American Society for Engineering Education, Albuquerque, NM. 
Table 1

Correlations, Means, Standard Deviations, and Internal Consistency Estimates for the Theoretical Variables

\begin{tabular}{lccccccccccc}
\hline Scales & 1 & 2 & 3 & 4 & 5 & 6 & 7 & 8 & $\underline{\mathrm{M}}$ & $\underline{\mathrm{SD}}$ & $\alpha$ \\
\hline 1. Collective Effic. & -- & & & & & & & & 7.05 & 1.64 & .96 \\
2. Self-Efficacy & .37 & -- & & & & & & & 6.48 & 1.52 & .88 \\
3. Outcome Expec. & .48 & .58 & -- & & & & & & 7.41 & 1.25 & .92 \\
4. Interests & .49 & .35 & .41 & -- & & & & & 3.59 & .69 & .81 \\
5. Educ. Goals & .36 & .37 & .48 & .39 & -- & & & & 4.38 & .97 & .96 \\
6. Social Support & .47 & .58 & .59 & .37 & .46 & -- & & & 3.92 & .70 & .90 \\
7. Social Barriers & -.09 & -.09 & -.09 & .07 & -.14 & .01 & -- & & 2.27 & 1.12 & .91 \\
8. Team Cohesion & .67 & .22 & .30 & .37 & .32 & .20 & -.19 & -- & 3.59 & .69 & .82 \\
9. Team Satisfac. & .80 & .28 & .41 & .47 & .33 & .38 & -.02 & .84 & 3.88 & .82 & .94 \\
\hline
\end{tabular}

Note. Collective Eff. = Collective Efficacy; Outcome Expec. = Outcome Expectations;

Educ. Goals $=$ Educational Goals; Team Satisfac. $=$ Team Satisfaction.

$\underline{\mathrm{N}}=157 . \quad{ }^{\mathrm{a}}$ Correlations $\geq|.19|$ are significant, $\mathrm{p}<.05$. 


\section{Figure Caption}

Figure 1. Hypothesized relations between collective efficacy beliefs, team environment, and personal and team outcomes.

\section{Biographical Information}

DR. ROBERT LENT, is a Professor of Counseling Psychology at the University of Maryland, College Park. His major research interests include career decision making factors and career theory. He is a member of the BESTEAMS group studying retention issues in engineering and sciences at the University of Maryland.

DR. LINDA SCHMIDT, is Associate Professor of Mechanical Engineering at the University of Maryland, College Park. Linda has been involved in engineering educational issues as a founding member of BESTEAMS and is the Principle Investigator on the NSF grant supporting the research reported here.

DR. JANET SCHMIDT, Director of Engineering Student Research, is a psychologist specializing in assessment issues, learning effectiveness, and promoting effective teamwork in the engineering classroom. She is also a member of BESTEAMS at the University of Maryland, College Park.

DR. GARY PERTMER, Associate Dean, Education and Associate Professor of Nuclear Engineering, is responsible for all matters related to undergraduate and graduate education: recruitment, admission, advising, special programs, retention, and accreditation. 


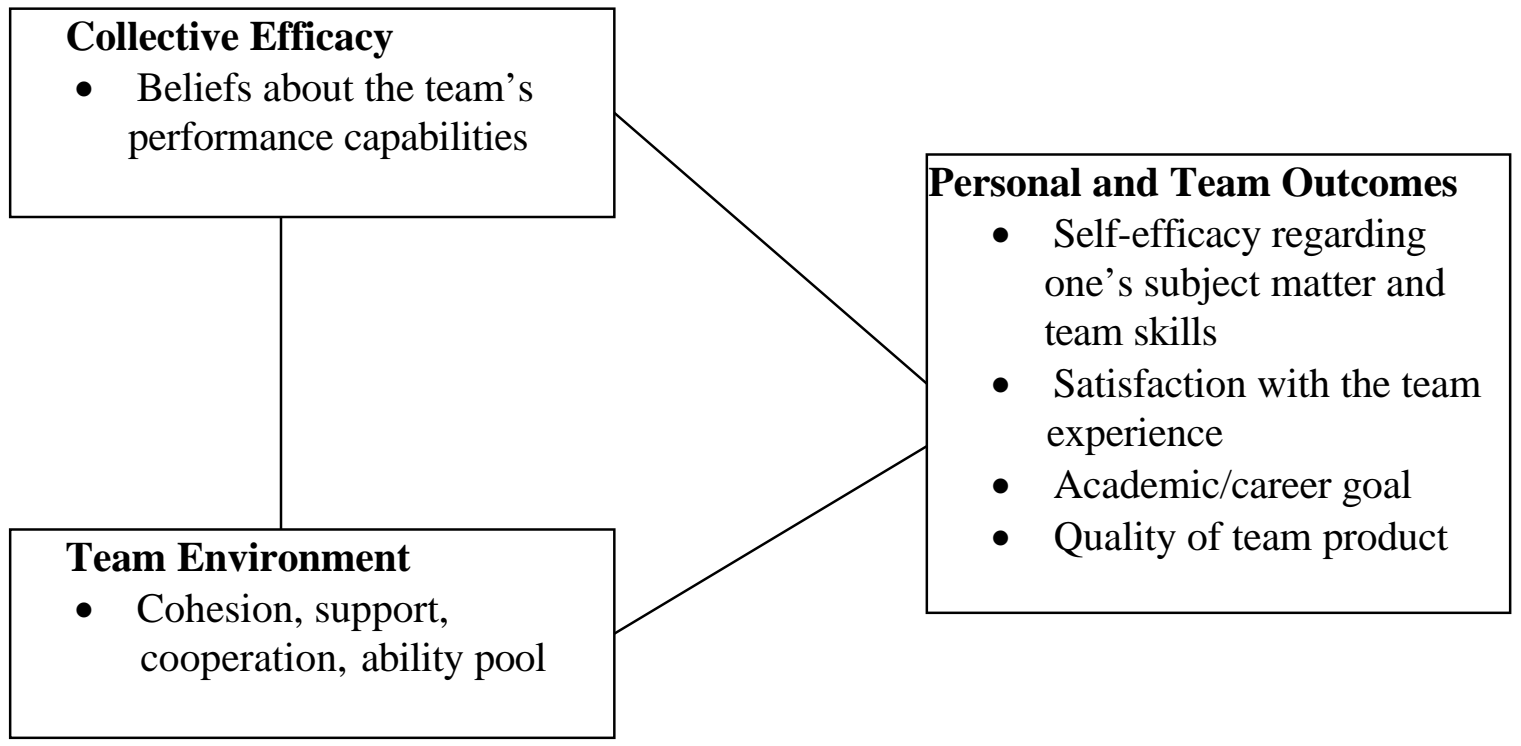

